Journal of Advanced Research in Fluid Mechanics and Thermal Sciences

Journal homepage: www.akademiabaru.com/arfmts.html ISSN: 2289-7879

\title{
The Effects of Nanosized-Palm Oil Fuel Ash on Early Age Hydration of Hardened Cement Paste: The Microstructure Studies
}

\author{
Mohd Azrul Abdul Rajak1, ${ }^{*}$, Zaiton Abdul Majid², Mohammad Ismail ${ }^{3}$ \\ Pusat Persediaan Sains \& Teknologi, Universiti Malaysia Sabah, Jln. UMS 88400, Kota Kinabalu, Sabah, Malaysia \\ Department of Chemistry, Faculty of Science, Universiti Teknologi Malaysia, Johor Bahru, Johor, Malaysia \\ Faculty of Civil Engineering, Universiti Teknologi Malaysia, Johor Bahru, Johor, Malaysia
}

ARTICLE INFO

Article history:

Received 13 January 2021

Received in revised form 18 April 2021

Accepted 20 April 2021

Available online 4 May 2021

\section{Keywords:}

Nanosized-palm oil fuel ash; pozzolanic reaction; cement hydration;

nanoparticles; supplementary cementing material

\section{ABSTRACT}

Integration of cement-based products with nanosized-palm oil fuel ash as supplementary cementing material (SCM) amend its hydration's degree at early age phase and the microstructural groundworks are relevant to explain the findings. Hence, the present work investigates the microstructure properties of the hardened cement paste (HCP) incorporating nPOFA to study on the effect of nPOFA in cement hydration at an early age phase. An Ordinary Portland Cement (OPC) paste as a set of HCP blended with microsized-palm oil fuel ash (mPOFA) (10-30\%) and nPOFA (10-60\%) were prepared and cured for 28 days. The microstructural examination of OPC, mPOFA and nPOFA cement pastes at 28 days curing age via Thermogravimetric (TG) analysis, X-Ray diffraction (XRD) analysis, morphology study and Fourier transform infrared (FTIR) spectroscopy analysis. In TG analysis, the relative weight loss of calcium hydroxide $(\mathrm{CH})$ of nPOFA pastes is lower than OPC and mPOFA. Based on the $\mathrm{CH}$ peaks at $2 \theta=18.1^{\circ}$ and $34.0^{\circ}$ in the diffractogram, it shows that nPOFA pastes give the low $\mathrm{CH}$ peaks compare to OPC and mPOFA pastes. In addition, the nPOFA pastes form the dense and compact microstructure of HCP compare to other pastes. Observations from FTIR analysis, nPOFA pastes display a high frequency of Si-O band due to the high rate of pozzolanic reaction. Overall, the findings confirmed the contribution of nPOFA in accelerating the rate of cement hydration and pozzolanic reaction as it reduced the amount of $\mathrm{CH}$ in the cementitious matrix.

\section{Introduction}

Early-age hydration is an important stage in developing the desired mechanical and durability performances of cement-based products. Yet, the external and internal cracking is significant damage during the early-age period. Previous literature states the factors include the tensile stress, change of environment, low water-to-binder ratio, alkali-aggregate reactions, and chloride ingression could lead to the extensive cracking $[1,2]$. Nevertheless, many studies with encouraging findings prove the potential of supplementary cementing materials (SCM) such as fly ash, rice husk ash, palm oil fuel ash (POFA) in enhancing the hydration of cement in early curing ages $[3,4]$.

\footnotetext{
* Corresponding author.

E-mail address: azrulrajak88@ums.edu.my
}

https://doi.org/10.37934/arfmts.82.2.8795 
The POFA is accepted as a pozzolanic material due to its siliceous-aluminous contents as it generates cementitious hydration products in the pozzolanic reaction with the calcium hydroxide $(\mathrm{CH})$ in the presence of moisture $[5,6]$. Many studies documented the application of POFA in improving the mechanical and durability of cement-based products [5-7]. Later, the potential of POFA as SCM has been optimized by increasing the fineness of particles into nanosized particles [8-10]. It is been reported the enhancement in mechanical and durability properties of cement-based products incorporate with nPOFA compared to the conventional POFA. Yet, the study focuses on the effect of nPOFA on the hydration of the early-age hardened cementitious matrix. Hence, the present work examines the microstructure properties of hardened cement paste (hcp) at 28 days curing age to explain the effect of nPOFA towards the degree of cement hydration at early-age period. In this study, the microstructure properties of hcp incorporate with nPOFA at 28 days curing age will be analyzed through the thermal analysis, X-Ray diffraction (XRD) analysis, morphology analysis, and Fourier Transform Infrared (FTIR) spectroscopy analysis.

\section{Experimental}

\subsection{Raw Materials}

As-received POFA (rPOFA) was collected at the local palm oil mill in Johor, Malaysia. The microsized POFA (mPOFA) was acquired from the grinding process of rPOFA by the modified Los Angeles Abrasion test machine [5-7] following the process to achieve the nanosized particles of POFA by subjecting mPOFA into a ceramic ball milling in $30 \mathrm{~h}$ by using 10:1 ball-to-specimen weight ratio [11]. The nPOFA was analyzed via Transmission electron microscopy (TEM). TEM analysis shows that nPOFA possesses the average particles in the range of 20 to $90 \mathrm{~nm}$ [8-10]. The chemical composition and physical properties of OPC, mPOFA, and nPOFA were shown in Table 1.

Table 1

Physical and chemical characteristics of mPOFA, nPOFA and OPC $[10,12]$

\begin{tabular}{llllllllll}
\hline Component & $\mathrm{SiO}_{2}$ & $\mathrm{CaO}$ & $\mathrm{Al}_{2} \mathrm{O}_{3}$ & $\mathrm{MgO}$ & $\mathrm{Fe}_{2} \mathrm{O}_{3}$ & $\mathrm{SO}_{3}$ & $\mathrm{LOI}$ & $\begin{array}{l}\mathrm{S}_{\mathrm{BET}} \\
{\left[\mathrm{m}^{2} / \mathrm{g}\right]}\end{array}$ & $\begin{array}{l}\text { True density } \\
{[\mathrm{g} / \mathrm{mL}]}\end{array}$ \\
\hline $\begin{array}{l}\text { mPOFA } \\
\text { nPOFA }\end{array}$ & 54.8 & 14.0 & 7.24 & 4.14 & 4.47 & 0.71 & 8.5 & 16.63 & 1.78 \\
OPC & 21.45 & 60.98 & 3.62 & 1.22 & 4.89 & 2.30 & 1.37 & - & - \\
\hline
\end{tabular}

\subsection{Preparation of Hardened Cement Paste}

The set of hcp incorporate with 10-30\% mPOFA and 10-60\% of nPOFA were prepared by using a water-to-binder ratio of 0.35 . In the meantime, the OPC paste was prepared as a control paste with a water-to-cement ratio of 0.28 . For the hardening purpose, the pastes were cast into $50 \mathrm{~mm} \times 50 \mathrm{~mm}$ $\times 50 \mathrm{~mm}$ moulds. The pastes were demolded after $24 \mathrm{~h}$ and stored in a saturation lime solution for 28 days. Then, the hcp cubes were crushed manually, and the hydration was arrested by immersing the hcp in acetone for 3 days.

\subsection{Microstructure Study of Hardened Cement Paste}

In this study, the hydration and pozzolanic reaction progress were investigated through the microstructural analysis includes the Thermogravimetric (TG) analysis, XRD analysis, morphology analysis and FTIR analysis. The thermogravimetric analysis was conducted using a Perkin-Elmir Thermal Pyris Diamond TG/DTA Analyzer. Experiments were carried on hcp specimens under 
dynamics conditions from room temperature up to $1000^{\circ} \mathrm{C}$ at a heating rate of $10^{\circ} \mathrm{C} / \mathrm{min}$ in a nitrogen atmosphere.

The XRD analysis was performed using a Siemens/Bruker Advance D5000 diffractometer with Cu $K \alpha$ radiation $(\lambda=1.54060 \AA)$. Diffractometer settings were $40 \mathrm{kV}, 25 \mathrm{~mA}$, a scan range of $2 \theta$ from $2^{\circ}$ to $70^{\circ}$, step size of $0.05^{\circ}$ and scan speed of $0.05^{\circ} / \mathrm{min}$ at room temperature. The morphology of small hcp fragments was captured using a Phenom ProX SEM and operated at $10 \mathrm{kV}$. The infrared spectra of hcp specimens were recorded in the range of $4000 \mathrm{~cm}^{-1}$ to $450 \mathrm{~cm}^{-1}$ using a Perkin Elmer Spectrum One FTIR spectrometer. A KBr-hcp pellet was prepared using hcp specimen to $\mathrm{KBr}$ ratio of 1:100.

\section{Result and Discussion}

The effect of nPOFA in the degree of cement hydration in hcp at early curing age will be discussed in this section based on the findings from the microstructural studies.

\subsection{Thermal Analysis}

The DTG curves of cement pastes and the relative loss weight of $\mathrm{CH}$ for OPC, mPOFA, and nPOFA hcp were shown in Figure 1(a) and Figure 2(b), respectively. Based on DTG thermograms in Figure 2(a), there are three substantial weight losses for all hcp which were detected in the temperature range of $30^{\circ} \mathrm{C}$ to $210^{\circ} \mathrm{C}, 410^{\circ} \mathrm{C}$ to $480^{\circ} \mathrm{C}$, and $510^{\circ} \mathrm{C}$ to 700 으. Respectively, these endoterm peaks correspond to the decomposition of the evaporation-water in capillary pores and dehydration hydrated products; dihydroxylation of $\mathrm{CH}$ and decarbonation of carbonated phases [13].

In this study, the rate of the cement hydration of hcp incorporates with nPOFA through the relative weight loss of $\mathrm{CH}$ in hcp. The relative weight loss of OPC, mPOFA and nPOFA at 28 days curing age are shown in Figure 1(b). As can be seen in Figure 1(b), the OPC hcp displays the weight loss of $\mathrm{CH}$ 4.3\%. In mPOFA hcp, the relative weight loss of $\mathrm{CH}$ in 10mPOFA, 20mPOFA and 30mPOFA hcp at 28 days curing age is $4.1 \%, 3.4 \%$ and $2.9 \%$, respectively. In nPOFA hcp, the relative weight loss of $\mathrm{CH}$ of 10nPOFA, 20nPOFA, 30nPOFA, 40nPOFA, 50nPOFA and 60nPOFA hcp at 28 days curing age are $3.7 \%, 3.2 \%, 2.6 \%, 2.3 \%, 2.2 \%$, and $2.2 \%$, correspondingly. It is also detected the reduction of relative weight loss of $\mathrm{CH}$ as the replacement amount of POFA increases. As shown in Eq. (1) and Eq. (2), $\mathrm{CH}$ is one of the hydration products as it contributes to a high $\mathrm{CH}$ amount in OPC hcp. Meanwhile, the consumption of $\mathrm{CH}$ in the pozzolanic reaction (see Eq. (3)) is attributed to a reducing amount of $\mathrm{CH}$ in mPOFA and nPOFA hcp. The different amount of $\mathrm{CH}$ between mPOFA and nPOFA is due to the fact that the nanoparticles of nPOFA accelerate the rate of cement hydration and pozzolanic reaction. 


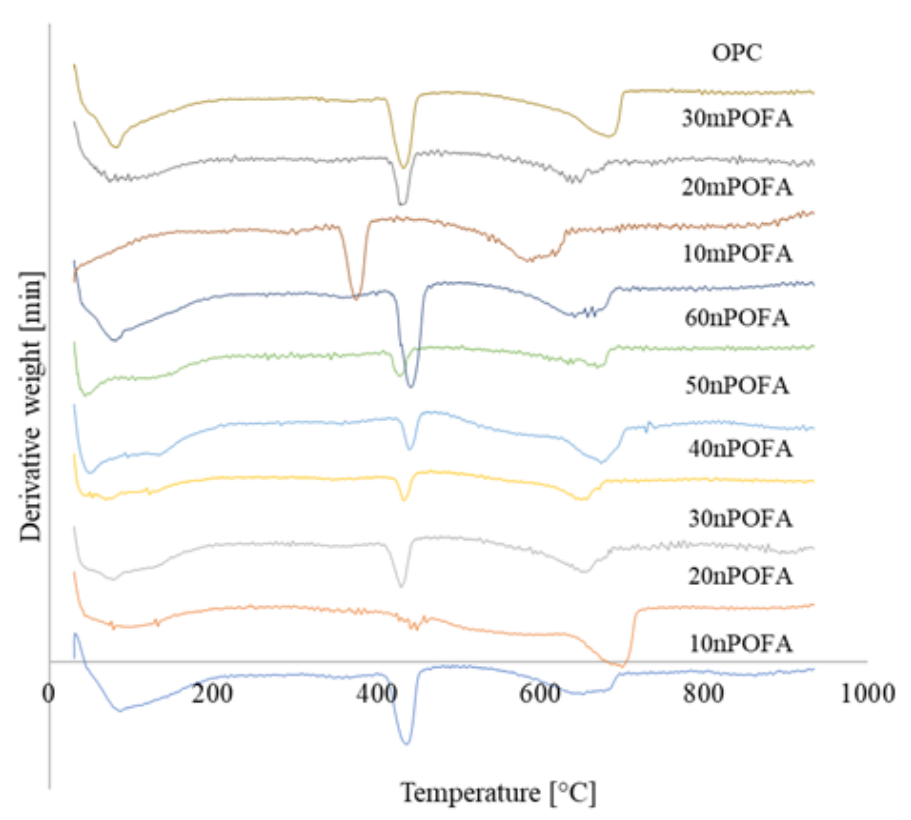

(a)

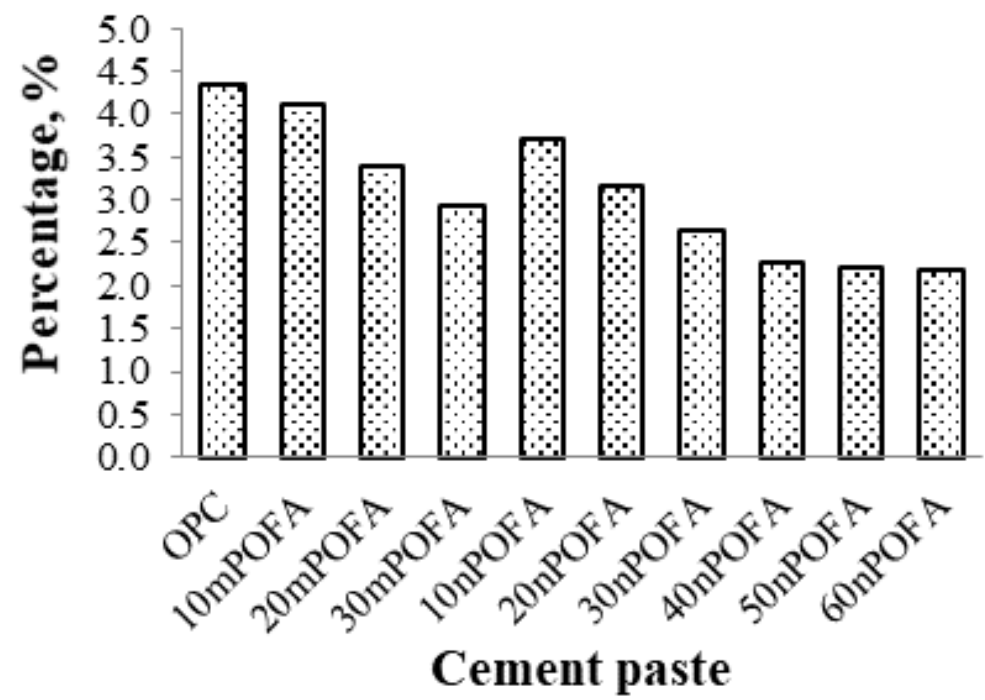

(b)

Fig. 1. (a) DTG curves of cements pastes at 28 days curing age and (b) relative loss weight of $\mathrm{CH}$ phase obtained from thermogram of OPC, mPOFA and nPOFA cement pastes at 28 days curing age

$2\left(3 \mathrm{CaO}^{-\mathrm{SiO}_{2}}\right)(\mathrm{s})+8 \mathrm{H}_{2} \mathrm{O}(\mathrm{l}) \rightarrow 6 \mathrm{Ca}^{2+}(\mathrm{aq})+10 \mathrm{OH}^{-}(\mathrm{aq})+2 \mathrm{H}_{3} \mathrm{SiO}_{4}^{-}(\mathrm{aq})$

$2\left(3 \mathrm{CaO} . \mathrm{SiO}_{2}\right)(\mathrm{s})+6 \mathrm{H}_{2} \mathrm{O}(\mathrm{I}) \rightarrow 3 \mathrm{CaO} \cdot 2 \mathrm{SiO}_{2} \cdot 3 \mathrm{H}_{2} \mathrm{O}(\mathrm{s})+3 \mathrm{Ca}(\mathrm{OH})_{2}(\mathrm{~s})$

$\mathrm{Ca}^{2+}(\mathrm{aq})+\mathrm{H}_{2} \mathrm{SiO}^{2-}(\mathrm{aq})+\mathrm{H}_{2} \mathrm{O}(\mathrm{l}) \rightarrow \mathrm{CaO}^{2} \mathrm{SiO}_{2} \cdot 2 \mathrm{H}_{2} \mathrm{O}(\mathrm{s})$ 


\subsection{X-Ray Diffraction Analysis}

Figure 2 shows the diffractogram of OPC hcp at 28 days curing age. The intense peak at $2 \theta=29.40$ is assigned to the overlap peaks of alite, calcite, and tobermorite (CSH). However, at this early curing age, the peaks might be subjected to the appearance of $C_{3} S$. Other intense peaks at $2 \theta=18.10$ and 34.1 o determine the existence of portlandite $(\mathrm{CH})$ in all hcp. Observation on these peaks, the OPC hcp has the highest peak intensity of $\mathrm{CH}$ compared to mPOFA and nPOFA hcp. In addition, the $\alpha$ quartz peaks at $2 \theta=26.5$ - were not observed in OPC hcp as it was detected in all mPOFA and nPOFA hcp. The findings could explain the effect of nPOFA on the degree of cement hydration through the qualitative examination on the peak, specifically based on the $\mathrm{CH}$ peaks. It is suggested that the low of $\mathrm{CH}$ peaks detected in MPOFA and nPOFA hcp is attributed to the reaction between POFA particles with $\mathrm{CH}$ to generate secondary $\mathrm{CSH}$. In addition, the low-intensity peaks in nPOFA hcp justified the significance of nanoparticles in increasing the rate of pozzolanic reaction. These findings were similarly discussed in thermal analysis. The existence of silica in mPOFA and nPOFA hcp is confirmed based on the appearance of the $\alpha$-quartz peak. These findings are in the agreement with the previous studies by other researchers.

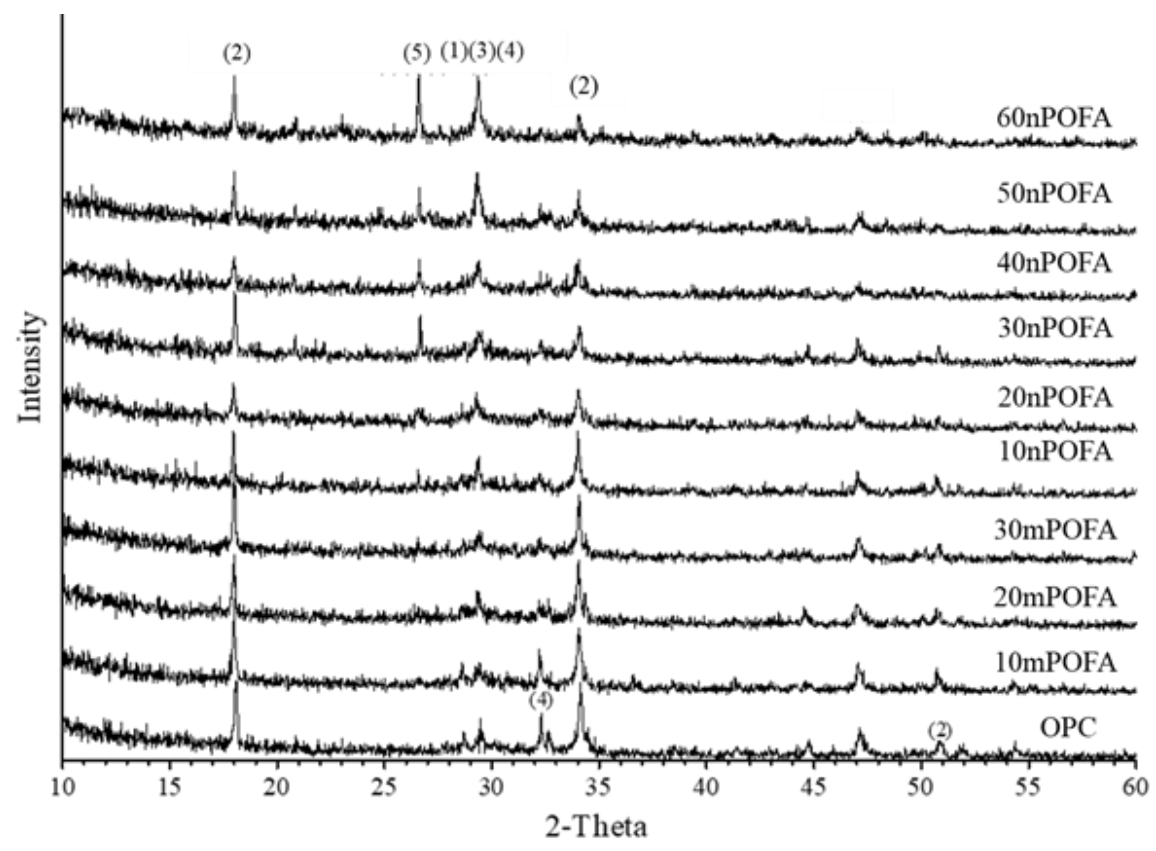

Fig. 2. Diffractogram of OPC, mPOFA and nPOFA hcp at 28 days curing age Notation- (1)Alite (2)Portlandite (3)Calcite (4)CSH (5) $\alpha$-quartz

\subsection{FTIR Analysis}

Figure 3 shows the FTIR spectrum of OPC, mPOFA and nPOFA hcp at 28 days curing age. A sharp peak in the range of 959 to $973.1 \mathrm{~cm}^{-1}$ is observed and the peaks correspond to the $\mathrm{Si}-\mathrm{O}$ asymmetric stretching vibration, resulted from the polymerization of silicate unit $\left(\mathrm{SiO}_{4}{ }^{4-}\right)$ which indicates the formation of $\mathrm{CSH}$ gel during the cement hydration. The appearance of the medium-strong peak around $3650 \mathrm{~cm}^{-1}$ is assigned to the $\mathrm{O}-\mathrm{H}$ is symmetric stretching vibration which arises from the generation of $\mathrm{CH}$. Other peaks with strong intensity at $1450 \mathrm{~cm}^{-1}$ and $875 \mathrm{~cm}^{-1}$ are the characteristic bands for $\mathrm{C}-\mathrm{O}$ stretching vibration and $\mathrm{C}-\mathrm{O}$ bending vibration, respectively. These peaks arise from the carbonate $\left(\mathrm{CO}^{3-}\right)$ group in calcite. 


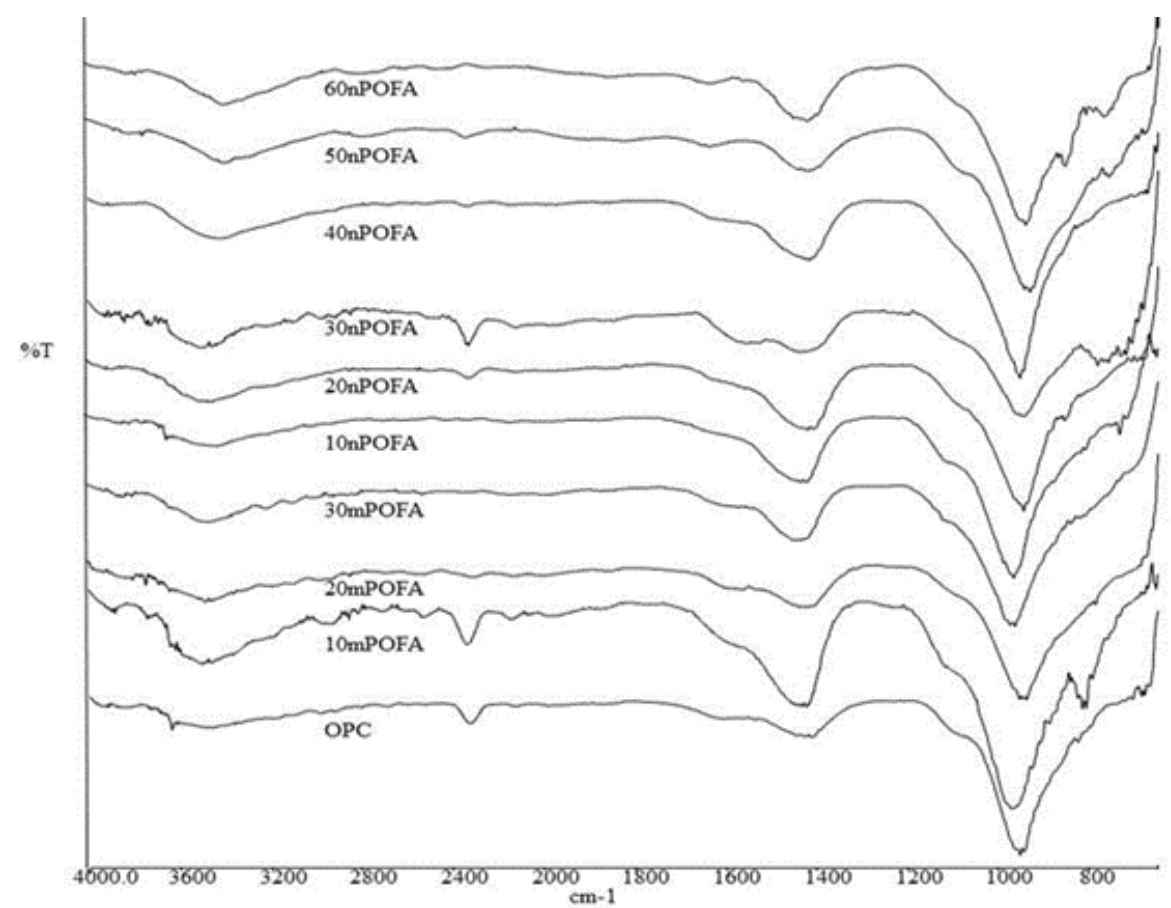

Fig. 3. FTIR spectrum of OPC, $10 \mathrm{mPOFA}, 20 \mathrm{mPOFA}, 30 \mathrm{mPOFA}, 10 \mathrm{nPOFA}$, 20nPOFA, 30nPOFA, 40nPOFA, 50nPOFA and 60nPOFA hcp at 28 days curing ages

Table 2 shows the wavenumbers of Si-O band from FTIR analysis. At 28 days curing age, most of Si-O bands in the mPOFA and nPOFA hcp show high frequencies than the OPC hcp. The hydration can be discussed growth based on the intensity progress of Si-O stretching vibration [14]. Thus, the high frequency in 20mPOFA, 30nPOFA and 40 nPOFA hcp can be explained by the high rate of cement hydration due to the presence of mPOFA and nPOFA particles (acceleration effect) and the formation of secondary CSH (pozzolanic reaction). In addition, it also could be attributed to the high rate of pozzolanic reaction to generate the secondary $\mathrm{CSH}$. This agreement was confirmed by the findings in the thermal analysis, as these hcp shows high $\mathrm{CH}$ consumption (see Figure 1(b)). Meanwhile, the hcp with a high replacement of mPOFA or nPOFA increases the dilution effect, as it could reduce the formation of $\mathrm{CSH}$ and the rate of pozzolanic reaction.

Table 2

Wavenumbers of peaks from FTIR analysis

\begin{tabular}{llllll}
\hline Assignment peaks & Cement pastes & & & & \\
\hline & OPC & 10mPOFA & 20 mPOFA & 30mPOFA & 10nPOFA \\
Si-O & 963.2 & 971.4 & 965.0 & 963.1 & 963.2 \\
& 20 nPOFA & 30nPOFA & 40 nPOFA & 50nPOFA & 60nPOFA \\
Si-O & 965.2 & 973.1 & 965.2 & 959.3 & 959.3 \\
\hline
\end{tabular}

\subsection{Morphology Analysis}

The morphology image of OPC, mPOFA, and nPOFA hcps was shown in Figure 4(a)-(f). The findings further confirm the thermal, mineralogical and infrared spectroscopy results. According to Figure 4(a)-(f), all hcp at 28 days curing age filled with the anhydrous cement and hardened hydration products. Yet, only mPOFA hcp displays the POFA particles as can be seen in Figure 4(b). The CSH could be observed based on the presence of fibrous hydrates on the platelet-like layers or irregular particles as well on the surface of anhydrous cement. The $\mathrm{CH}$ is detected in the form of various 
hexagonal plates of flakes. In addition, it is been observed that the $\mathrm{CH}$ plates in 20mPOFA, 20nPOFA, 30nPOFA and 40nPOFA hcp (see Figure 4(b)-(e)) are covered with fibrous CSH. It is proposed that the fibrous $\mathrm{CSH}$ on the $\mathrm{CH}$ surfaces are formed from the pozzolanic reaction. The presence of ettringite also been detected in OCP hcp (see Figure 4(a)) as it presents as a thin and long needle-like phase. Meanwhile, as can be seen in Figure 4(b), the POFA particles are embedded with the hydrated products. It shows that the POFA particles act as nucleation sites for hydration and pozzolanic reaction products. It can be seen in Figure 4(c)-(e), the 20nPOFA, 30nPOFA and 40nPOFA hcp display a dense and compact microstructure compare to the OPC and nPOFA hcp. However, the 50nPOFA (see Figure 4(f)) hcp show a low dense and compact microstructure at this curing age.

It is suggested that the distribution of nPOFA on the hardened cementitious matrix lead to the optimum potential due to its high fineness, as well as reinforce its ability to act as nucleation sites and filler. Furthermore, its small diameter particles and high specific surface area (see Table 1), resulting in the high dissolution of both crystalline and amorphous silica in the pores solution as it accelerates the rate of cement hydration and pozzolanic reaction. Consequently, it enhances the microstructure of the hardened cementitious matrix into a dense and compact microstructure compared to OPC and mPOFA.

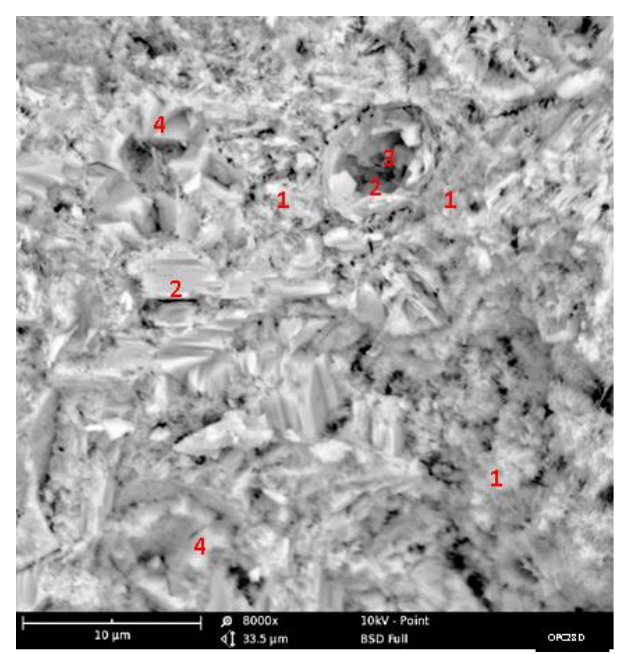

(a)

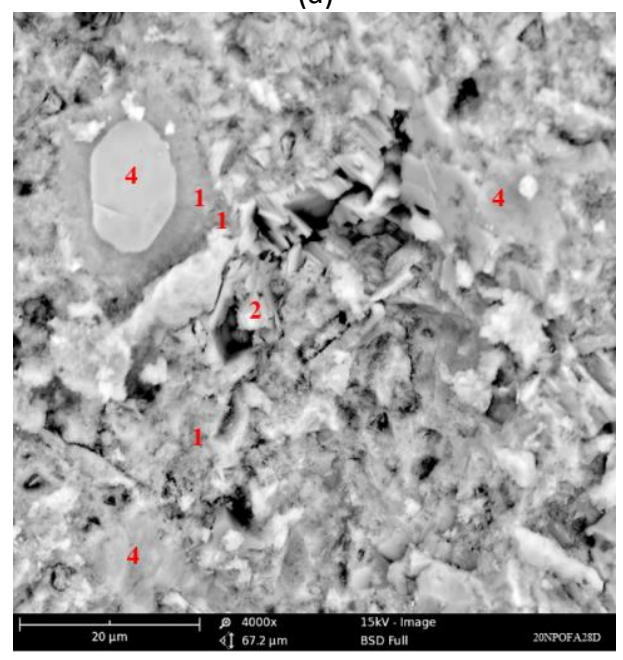

(c)

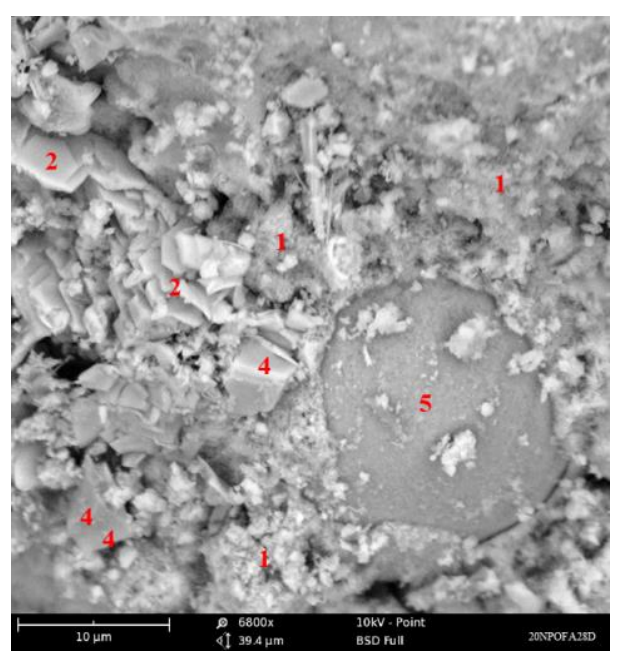

(b)

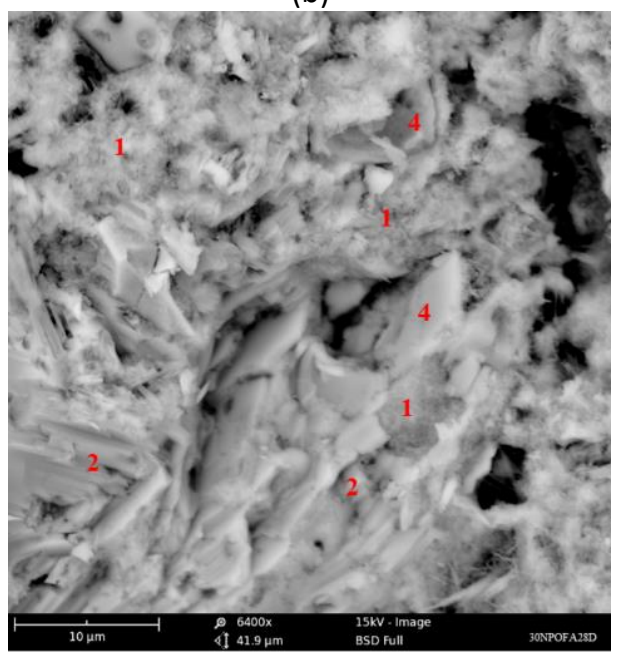

(d) 


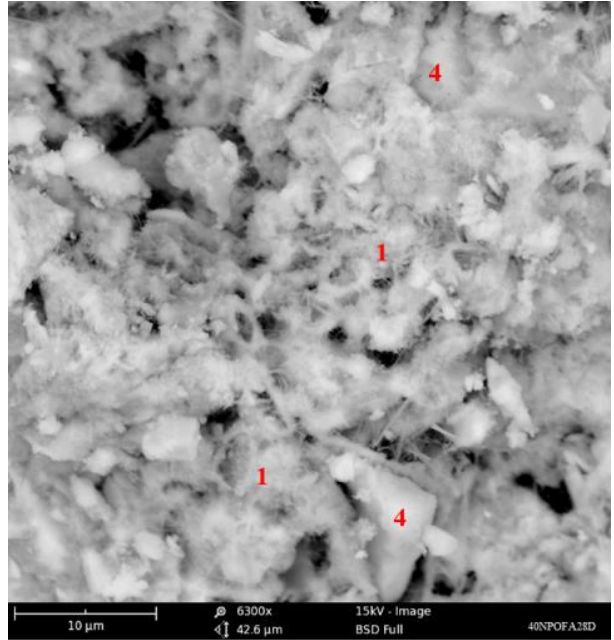

(e)

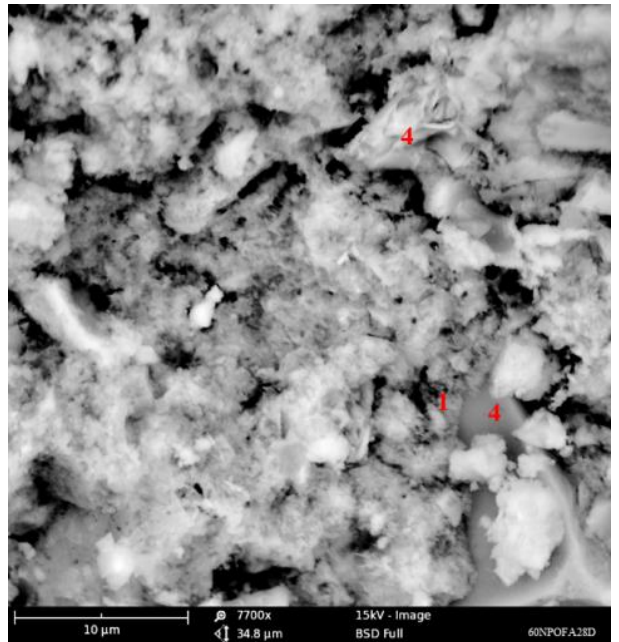

(f)

Fig. 4. SEM micrographs of (a) OPC (b) 20mPOFA, (c) 20nPOFA (d) 30nPOFA (e) 40nPOFA and (f) 60nPOFA at 28 days curing age

Notation: 1-CSH, 2-CH, 3- Ettringite, 4- Alite/Belite, 5- POFA particles

\section{Conclusions}

Based on the microstructure analyses, the findings examined the effect on nPOFA in the cement hydration in the hardened cementitious matrix. The high $\mathrm{CH}$ consumption in nPOFA hcp through thermal analysis shows that the high rate of cement hydration and pozzolanic reaction. In addition, the low-intensity peaks of portlandite at $2 \theta=18.1^{\circ}$ and $34.1^{\circ}$ in nPOFA hcp confirmed the high $\mathrm{CH}$ consumption in pozzolanic reaction. As the high frequency in Si-O band in 30mPOFA, 30nPOFA and 40nPOFA hcp indicate the high rate of CSH formation in hcp compare to OPC hcp. Meanwhile, the dense and compact structure in 30nPOFA and 40nPOFA hcp shows the high fineness of nPOFA particles accelerates its dissolution and rate of reaction with $\mathrm{CH}$ to generate secondary $\mathrm{CSH}$, as it increases the ability of POFA as nucleation sites and filler. These findings confirm that the presence of nPOFA enhanced the cement hydration in the early-age of the hardened cementitious matrix as it could improve the mechanical and durability of cement-based products.

\section{Acknowledgements}

The authors would like to acknowledge Department of Chemistry, Faculty of Science \& Department of Structure and Materials, Faculty of Civil Engineering, Universiti Teknologi Malaysia. The authors also thank Universiti Malaysia Sabah for the financial supports.

\section{References}

[1] Khan, Inamullah, Tengfei Xu, Arnaud Castel, Raymond lan Gilbert, and Mahdi Babaee. "Risk of early age cracking in geopolymer concrete due to restrained shrinkage." Construction and Building Materials 229 (2019): 116840. https://doi.org/10.1016/i.conbuildmat.2019.116840

[2] Shen, Dejian, Yang Jiao, Yan Gao, Shuaishuai Zhu, and Guoqing Jiang. "Influence of ground granulated blast furnace slag on cracking potential of high performance concrete at early age." Construction and Building Materials 241 (2020): 117839. https://doi.org/10.1016/i.conbuildmat.2019.117839

[3] Siddique, Rafat, and Mohammad Iqbal Khan. Supplementary cementing materials. Springer Science \& Business Media, 2011. https://doi.org/10.1007/978-3-642-17866-5

[4] Lothenbach, Barbara, Karen Scrivener, and R. D. Hooton. "Supplementary cementitious materials." Cement and concrete research 41, no. 12 (2011): 1244-1256. https://doi.org/10.1016/i.cemconres.2010.12.001 
[5] Hamada, Hussein M., Gul Ahmed Jokhio, Fadzil Mat Yahaya, Ali M. Humada, and Yasmeen Gul. "The present state of the use of palm oil fuel ash (POFA) in concrete." Construction and Building Materials 175 (2018): 26-40. https://doi.org/10.1016/i.conbuildmat.2018.03.227

[6] Thomas, Blessen Skariah, Sanjeev Kumar, and Hasan Sahan Arel. "Sustainable concrete containing palm oil fuel ash as a supplementary cementitious material-A review." Renewable and Sustainable Energy Reviews 80 (2017): 550561. https://doi.org/10.1016/i.rser.2017.05.128

[7] Mujedu, Kasali Adebayo, Mariyana Aida Ab-Kadir, and Mohammad Ismail. "A review on self-compacting concrete incorporating palm oil fuel ash as a cement replacement." Construction and Building Materials 258 (2020): 119541. https://doi.org/10.1016/i.conbuildmat.2020.119541

[8] Hamada, Hussein, Bassam Tayeh, Fadzil Yahaya, Khairunisa Muthusamy, and Alyaa Al-Attar. "Effects of nano-palm oil fuel ash and nano-eggshell powder on concrete." Construction and Building Materials 261 (2020): 119790. https://doi.org/10.1016/i.conbuildmat.2020.119790

[9] Rajak, Mohd Azrul Abdul, Zaiton Abdul Majid, and Mohammad Ismail. "Morphological characteristics of hardened cement pastes incorporating nano-palm oil fuel ash." Procedia Manufacturing 2 (2015): 512-518. https://doi.org/10.1016/i.promfg.2015.07.088

[10] Rajak, M. A. A., Z. A. Majid, and M. Ismail. "Pozzolanic activity of nanosized palm oil fuel ash: A comparative assessment with various fineness of palm oil fuel ash." In IOP Conference Series: Earth and Environmental Science, vol. 220, no. 1, p. 012061. IOP Publishing, 2019. https://doi.org/10.1088/1755-1315/220/1/012061

[11] Khalil, HPS Abdul, H. M. Fizree, M. Jawaid, and Omar S. Alattas. "Preparation and characterization of nano structured materials from oil palm ash: a bio-agricultural waste from oil palm mill." BioResources 6, no. 4 (2011): 4537-4546.

[12] Rajak, Mohd Azrul Abdul, Zaiton Abdul Majid, and Mohammad Ismail. "Cement Hydration Extents for Hardened Cement Paste Incorporating Nanosized-Palm Oil Fuel Ash: A Thermal and XRD Analysis Study." In ICACE 2019, pp. 61-70. Springer, Singapore, 2020. https://doi.org/10.1007/978-981-15-1193-6 7

[13] Deboucha, Walid, Nordine Leklou, Abdelhafid Khelidj, and Mohamed N. Oudjit. "Hydration development of mineral additives blended cement using thermogravimetric analysis (TGA): Methodology of calculating the degree of hydration." Construction and Building Materials $146 \quad$ (2017): https://doi.org/10.1016/i.conbuildmat.2017.04.132

[14] Kontoleontos, F., P. E. Tsakiridis, A. Marinos, V. Kaloidas, and M. Katsioti. "Influence of colloidal nanosilica on ultrafine cement hydration: Physicochemical and microstructural characterization." Construction and building materials 35 (2012): 347-360. https://doi.org/10.1016/i.conbuildmat.2012.04.022 